\title{
EVAPORATION OF BODY WATER IN LOBAR PNEUMONIA ${ }^{1}$
}

\author{
By GEORGE K. ANDERSON \\ (From the Departments of Physiology and Pediatrics, University of Rochester School of \\ Medicine and Dentistry, Rochester, N. Y.)
}

(Received for publication, January 24, 1938)

In order to maintain a constant body temperature the heat loss must equal the heat production. The modes of heat loss are by radiation, conduction, convection, and water evaporation. This last varies greatly according to the bodily requirements. Certain modifications in the rate of evaporation, concomitant with fever, are the subject of discussion in this paper.

The non-renal loss of water, often called insensible loss, consists of water evaporated from the skin and from the respiratory passages. Benedict and Root (1) showed that the total evaporation rate parallels the oxygen consumption so closely that under limited conditions it serves as a measure of the energy metabolism of the body. Benedict and Root determined that the loss from the lungs among a variety of human individuals averages 35 per cent of the total insensible water loss in the resting individual.

Since the insensible perspiration so closely parallels the oxygen consumption in health, it has been of interest to determine any changes induced during fever. Leyden (2) was one of the earliest investigators to demonstrate by daily determinations of body weight, a retention of water during fever. The first measurements in pneumonia of evaporation from the body surface, exclusive of the head, were recorded by Schwenkenbecher (3). From a patient with lobar pneumonia he found less evaporation at the temperature of $39.9^{\circ}$ C. than on the morning after the crisis when the temperature was $37.6^{\circ} \mathrm{C}$. Other investigators recorded a greater rate of water loss during certain stages of fever than in the normal state.

Sandelowsky (4) reported seven cases of lobar pneumonia in which there was a decrease in body weight appearing concurrently with the disappearance of the fever. A concentration of the blood was found along with the decreased body weight. Sandelowsky considers this as evidence of rapid

1 Aided by a grant from the Fluid Research Fund of this School. loss of water from the blood and body tissues. At the same time this author reports three cases out of ten which show no such change.

Lussky and Friedstein (5) associated a loss of body weight at the time of defervescence in twenty-nine cases of lobar pneumonia in infants with a water retention during the febrile period.

Sunderman and Austin (6) made careful observations on the water balance in six cases of lobar pneumonia. They concluded that there is a negative balance of water in most cases of lobar pneumonia under routine care, and either a decrease in negative, or else a positive, water balance when pneumonia patients are given plentiful $\mathrm{NaCl}$ in their diets.

Ribadeau-Dumas and Meyer (7) reported determinations of water evaporation in cases of bronchopneumonia in infants. Weighing the child for one-half or one hour periods on a balance sensitive to $1 \mathrm{gram}$, they find that in most cases the perspiration is increased 40 to 60 per cent over normal, with resulting weight loss, while in two cases considerably diminished perspiration and some edema are found.

\section{EXPERIMENTAL PROCEDURE}

The subjects of these observations were children in the Pediatric Divisions of the Strong Memorial and Rochester Municipal Hospitals under routine care for lobar pneumonia, on diets consisting chiefly of fluids during the febrile period. The children were carried from their beds into a room having a slow circulation of air from a conditioning unit within the insulated room with a constant temperature of $28^{\circ} \mathrm{C}$. and approximately 35 per cent relative humidity. The children usually wore no more than a pair of trunks and were placed upon a rubber sheet on the Sauter balance. This balance is sensitive to 0.1 gram and has a double-swing period of approximately 30 seconds. The time required for the loss of 2 grams of weight in small children and 5 grams in older children, taken in one or sometimes two suc- 
cessive periods, determined the water evaporation in grams per hour. After entering the room, a period of 5 to 10 minutes elapsed before the weighing was made while the child became relaxed and accustomed to his surroundings.

When a separation of insensible loss into loss from skin and loss from lungs was desired, the subject was made to breathe through flutter valves to a bottle of 4 to 8 mesh pumice stone saturated with concentrated $\mathrm{H}_{2} \mathrm{SO}_{4}$. This bottle rode upon the patient's side of the balance and collected the water of the expired air. The difference in weight before and after collection of respiratory water vapor was then determined.

Actual body weight was determined at the time of evaporation measurements. So far as possible, the weighings were done at the same hour each day to exclude the effects of excitement, baths, or recent meals. Since the patients were available for study only while in the hospital, the stay in some cases was too short for complete return to a healthy state and for comparison with the febrile period.

\section{RESULTS}

Seven cases of lobar pneumonia in children were studied. In two of these, partition of the lung and skin evaporation was made. The results in these seven uncomplicated cases show that the vaporization of water ran typical courses, one of which is represented graphically in Figure 1.

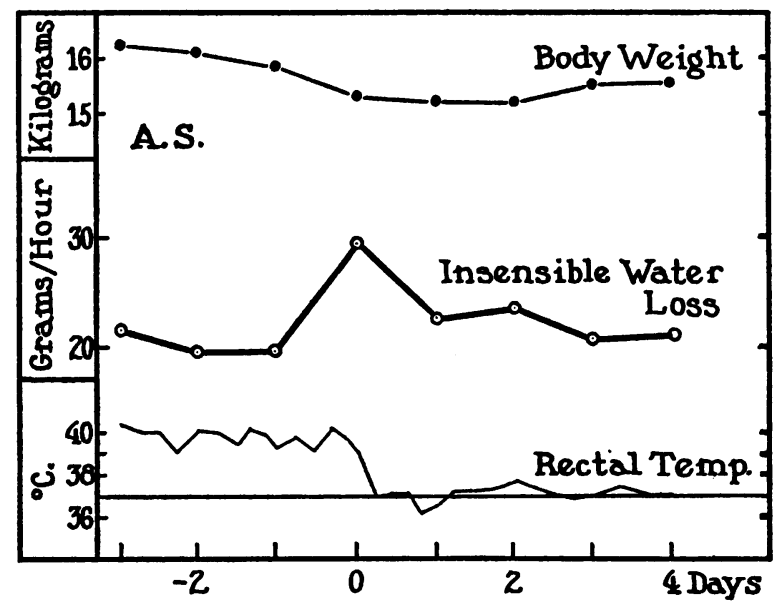

Fig. 1. Patient A. S. Daily Relation of Insensible Water Loss to Body Weight aNd Rectal Temperature in Lobar Pneumonia.
The patients were first studied in the febrile state. Comparison of the rate of water evaporation at this time with that determined in the late recovery period showed an increase in body evaporation during the fever in five cases, no change in one, and a slightly lower value in an other. The average departure from normal (late recovery period) was a 10 per cent increase.

Since the patients were not available during the development of the fever, the changes in evaporation rate which might be observed at that time may be inferred from the values found during the subsequent fall of the temperature, and from measurements made upon isolated instances of rising temperature as found in two cases of bronchopneumonia and one case with a daily spiking fever of unknown etiology. These unrecorded observations and the changes to be subsequently described which are found during the abatement of fever all indicate a definite decrease in rate of evaporation during the development of fever.

If, during fever, this body temperature remains constant, the rate of evaporation varies but little; but with either a rise or a fall of rectal temperature, the vaporization rate is markedly altered, showing a rise during a drop in temperature. At the time of the crisis, as the temperature starts to fall, the insensible perspiration becomes sensible perspiration. This change, seen as the peak upon the chart, usually reaches its maximum within the 12 hours following the onset of defervescence, although in two cases it was not recorded until the second day following the crisis. This may be attributable to the infrequency of measurements. The average increased rate of water loss during the crisis as compared to that in the late recovery period is +47 per cent. Following this critical period, the rate of evaporation gradually returns to the basal value over a period of 3 to 4 days.

On the charts are shown the daily determinations of body weight. With the children partaking of fluids almost exclusively, and thus having a low caloric intake, the highest value appears just before the subsidence of the fever (best shown in Figure 2). Just after the crisis with its heightened vaporization, the body weight shows a sudden decrease and does not recover until two or more days after the crisis. It would seem as 


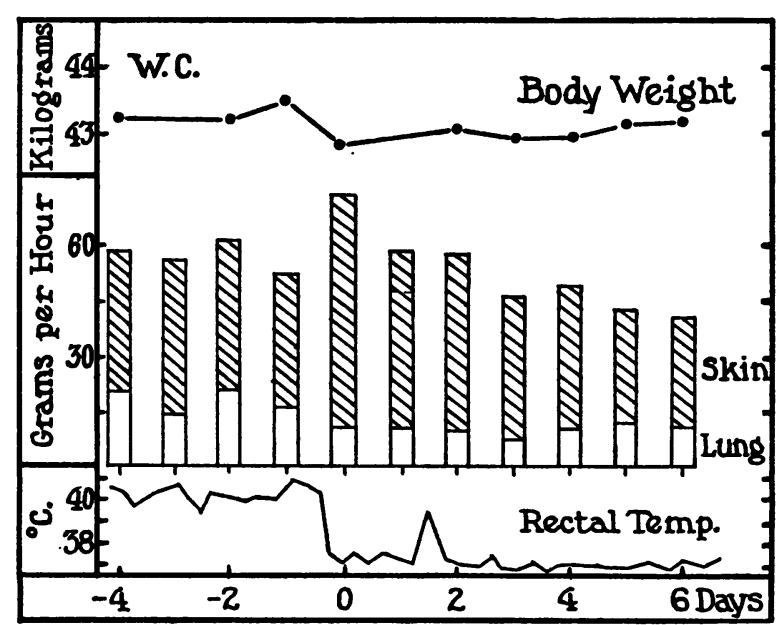

Fig. 2. Patient W. C. Daily Relation of Skin and Lung Fractions of Water Loss to Body Weight and Rectal Temperature in Lobar Pneumonia.

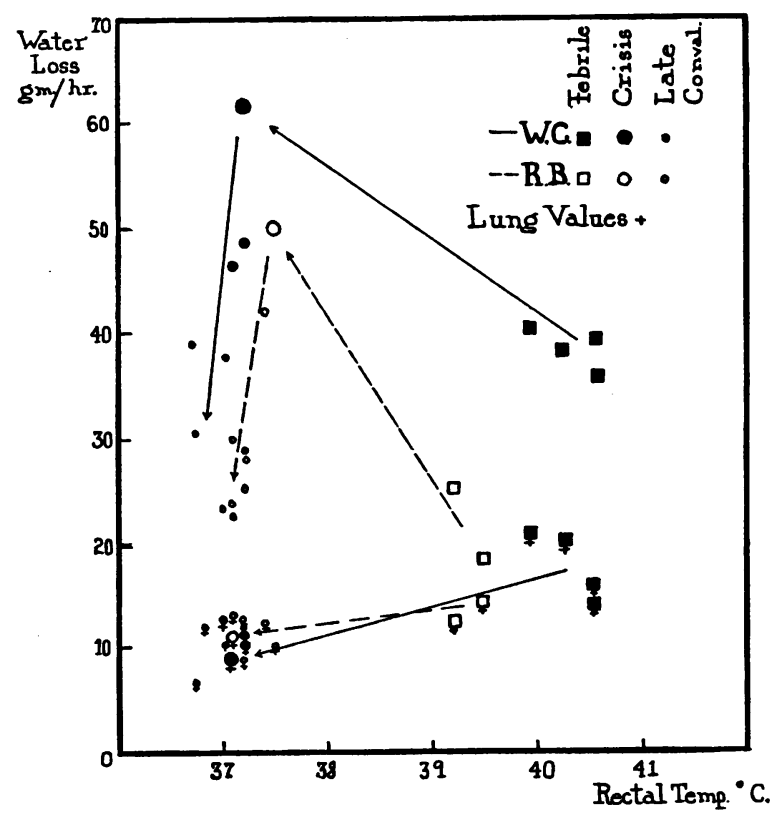

Fig. 3. Relation of Water Lost through Skin (ABOVE) and Water Lost From Lungs (Below) to the Rectal Temperatures in Two Cases of Lobar PneuMONIA.

Arrows indicate sequences of successive measurements.

if the sudden body weight loss and the body water loss were two measurements of the same thing.

In two cases, simultaneous determinations of skin and lung water loss were made. Case W. C. in Figure 2 shows the greatest febrile increase in total insensible water loss, being an increase of 26 per cent over normal. The fraction lost from the skin is decreased relative to increased total skin and lung loss at this time. The highest values for the lung evaporation are recorded during the fever state, giving a skin to lung ratio of $2: 1$. During the crisis, the skin loss increases greatly and the lung evaporation decreases to make a ratio of $6: 1$. Subsequently the skin loss decreases over 3 to 4 days until the nearly constant value is reached. The lung loss remains quite constant through convalescence, the last measurements showing a skin to lung ratio of $3: 1$.

TABLE I

Insensible water loss on successive days, divided into three arbitrary periods, in seven cases of lobar pneumonia. (Numbers represent grams per square meter per hour.)

\begin{tabular}{|c|c|c|c|c|c|c|}
\hline \multirow{2}{*}{$\underset{\text { tient }}{\mathrm{Pa}-}$} & \multirow{2}{*}{ Age } & \multirow{2}{*}{$\begin{array}{l}\text { Sur- } \\
\text { face } \\
\text { area } \\
\text { sq. } \\
\text { me- } \\
\text { ters }\end{array}$} & Fever & Crids & \multirow[b]{2}{*}{$\begin{array}{cc}\text { Day } & \text { Day } \\
\mathbf{2} & \mathbf{3}\end{array}$} & $\begin{array}{l}\text { Late con- } \\
\text { valescence }\end{array}$ \\
\hline & & & $\mid \begin{array}{llll}\text { Day Day Day Day } & -2 & -1 \\
-4 & -3 & -2\end{array}$ & $0^{\text {Day }}$ & & $\begin{array}{ccc}\text { Day } & \text { Day } & \text { Day } \\
4 & 6\end{array}$ \\
\hline $\begin{array}{l}\text { W. C. } \\
\text { R.B. } \\
\text { R.B. } \\
\text { A. C. } \\
\text { S. R. } \\
\text { A. B. } \\
\text { J. D. }\end{array}$ & \begin{tabular}{|c|} 
vears \\
8 \\
13 \\
10 \\
5 \\
9 \\
5 \\
14
\end{tabular} & $\begin{array}{l}1.26 \\
1.19 \\
1.12 \\
0.76 \\
0.98 \\
0.71 \\
1.48\end{array}$ & \begin{tabular}{|rrr}
$46.5+45.0$ & 48.5 & 41.1 \\
28.0 & 37.3 \\
20.1 & 29.1 \\
& 30.9 \\
37.0 & 34.1 \\
30.4 & 28.6 & 28.6 \\
28.4 & 32.4 & 25.0
\end{tabular} & 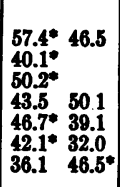 & $\begin{array}{|ll|}46.0 & 36.1 \\
& 30.3 \\
32.2 & \\
58.1 * & 46.4 \\
35.0 & 33.2 \\
33.1 & 29.2 \\
39.2 & \end{array}$ & \begin{tabular}{|lll}
38.7 & 33.4 & 31.1 \\
23.8 & 25.7 & 25.2 \\
24.9 & 22.5 & \\
41.6 & 37.7 & 34.3 \\
37.2 & & 35.4 \\
29.6 & & \\
29.6 & & \\
29.8
\end{tabular} \\
\hline $\begin{array}{l}\text { Mean } \\
\text { Means } \\
\text { mea }\end{array}$ & of $\mathrm{da}$ & & $\begin{array}{c}34.632 .532 .4 \\
33.1\end{array}$ & $\begin{array}{c}45.2428 \\
44.0\end{array}$ & $40.5 \quad 35.0$ & $\begin{array}{c}33.629 .130 .1 \\
30.1\end{array}$ \\
\hline
\end{tabular}

* The highest value measured, usually at time of crisis. $\dagger$ This figure is not included in the averages.

\section{DISCUSSION}

The rate of water evaporation cannot be used as a measure of body metabolism in lobar pneumonia. One investigator reports an increase of as much as 50 per cent in oxygen consumption during lobar pneumonia (8) while the water evaporation studies presented here show an average increase of 10 per cent during the fever. There is obviously a shift in heat loss by water vaporization, for water is not eliminated in proportion to water intake (6) nor to the rate of energy metabolism. The main source of upset in water loss is seen in the diminished skin evaporation. This decreased evaporation may be a factor in the rise of body temperature which in turn produces a rise in energy metabolism. One explanation for this decreased evaporation from the skin may be found in the peripheral vasoconstriction noted in human capillaries by FremontSmith et al. (9) at the onset of fever. The chill 
so often experienced at the onset of febrile lobar pneumonia in humans may be owing to this cutaneous vasoconstriction.

While a large component of the heat and water losses, the water evaporation from the skin, is underfunctioning, the loss from the lungs becomes increasingly efficient. This is due to the elevated body temperature and hence greater vapor tension of the expired air, and to the increased ventilation afforded by the rapid shallow respirations of lobar pneumonia (10). The increased respiratory water loss with rapid shallow respirations is described by Christie and Loomis (11). They suggest that this type of respiration excessively ventilates those parts of the lungs below the bronchi and above the alveoli to produce "a water loss out of proportion to the $\mathrm{CO}_{2}$ loss."

While the heat loss by water evaporation is deficient during fever, that share of the heat lost by radiation, conduction, and convection is increased and may be said to be proportional to the body temperature. Measurements made by the author by taking two or three consecutive thermocouple readings from several skin areas show an average rise of one degree skin temperature for each degree rise in rectal temperature in lobar pneumonia.

A balance is made by the elevated energy metabolism and faulty skin evaporation on one hand and the increased skin radiation and respiratory vaporization on the other, such that the body temperature levels off at the persistent high value of the fever state.

At the time of the crisis, the temperature falls rapidly. This is accomplished by a rapid vaporization of water from the skin; it is only by this means that the heat can be lost as rapidly as it is. An opinion might be expressed that in lobar pneumonia the changes in skin evaporation appear to allow a more rapid abatement than development of the high fever.

\section{SUM MARY}

1. An increase in the body weight during the fever of lobar pneumonia in children is found.
2. The insensible water loss through the skin as measured on a Sauter balance is less than normal in amount during the rise of the fever (determined in fevers other than lobar pneumonia), closely approximates normal skin values during the maintained fever, and is markedly elevated at the time of the crisis and gradually decreases for 3 to 4 days thereafter.

3. The lung vaporization is highest during the febrile period, taking over in part the deficient heat loss of the skin at this time.

4. The average skin temperature from several areas shows one degree rise for each degree rise in rectal temperature.

Grateful appreciation is expressed to Dr. E. F. Adolph and Dr. S. W. Clausen for their many valuable criticisms and suggestions in the course of this work.

\section{BIBLIOGRAPHY}

1. Benedict, F. G., and Root, H. F., Insensible perspiration; its relation to human physiology and pathology. Arch. Int. Med., 1926, 38, 1.

2. Leyden, E., Untersuchen über das Fieber. Deutsches Arch. f. klin. Med., 1869, 5, 273.

3. Schwenkenbecher, Uber die Ausscheidung des Wassers durch die Haut von Gesunden und Kranken. Deutsches Arch. f. klin. Med., 1903-04, 79, 29.

4. Sandelowsky, J., Blutkonzentration bei Pneumonie. Deutsches Arch. f. klin. Med., 1909, 96, 445.

5. Lussky, H. O., and Friedstein, H., Water retention in pneumonia. Am. J. Dis. Child., 1920, 19, 337.

6. Sunderman, F. W., and Austin, J. H., Studies of serum electrolytes. VI. Water metabolism in pneumonia. Am. J. M. Sc., 1930, 179, 167.

7. Ribadeau-Dumas, L., and Meyer, J., Etude du Métabolisme de l'Eau. Ann. de méd., 1924, 16, 125.

8. Riethus, O., Beobachtungen über den Gaswechsel kranker Menschen und den Einfluss antipyretischer Medicamente auf denselben. Arch. f. exper. Path. u. Pharmakol., 1900, 44, 239.

9. Fremont-Smith, F., Morrison, L. R., and Makepeace, A. W., Capillary blood flow in man during fever. J. Clin. Invest. (Proc.), 1929, 7, 489.

10. Meakins, J. C., and Davies, H. W., Respiratory Function in Disease. Oliver and Boyd, Edinburgh, 1925 , p. 218.

11. Christie, R. V., and Loomis, A. L., The pressure of aqueous vapor in alveolar air. J. Physiol., 1932, 77, 35 . 